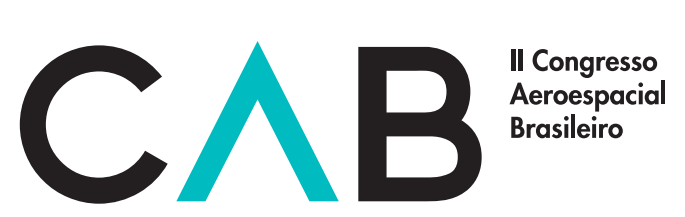

De 16 a 19

de setembro

\title{
EVALUATION OF THE READINESS OF THE AIT ORGANIZATION ARTIFICIAL SATELLITES APPLIED FOR STAKEHOLDERS REQUIREMENTS
}

\begin{abstract}
Isomar Lima ${ }^{a}$; Andreia Genaro ${ }^{b}$ José Wagner $^{c}$; Elaine de Paula ${ }^{d}$
[a] PhD Student in Space Engineering and Technology - National Institute of Space Research-INPE, São José dos Campos - SP, Brazil

[b] PhD in Space Engineering and Technology - National Institute of Space Research-INPE, São José dos Campos SP, Brazil

[c,d] Master Student in Space Engineering and Technology - National Institute of Space Research-INPE, São José dos Campos - SP, Brazil

Resumo: The activities of Assembly, Integration and Testing of an artificial satellite corresponds to a set of procedures and the execution of the logically correlated events sequenceto obtain a high degree of confidence of satellite operation. The Assembly, Integration and Testing (AIT) activities are performed to ensure that all specified design and performance parameters were reached. Within this context, all the environmental conditions in which the satellite will be asked for, from its launch until its operation in orbit, are simulated. The study presented herein is part of a Ph.D. research, with the purpose of developing a conceptual framework and a methodology for analysis of the AIT organization readiness level to integrate a particular satellite in order to satisfy all stakeholders' requirements (AIT stakeholders) valuing quality, reliability, safety and compliance of performance parameters usually adopted by the AIT organization.
\end{abstract}

Keywords: AIT, Stakeholders, Requirements, Readiness, Organization.

\section{INTRODUCTION}

This paper discusses the readiness assessment of the AIT (Assembly, Integration and Testing) organization for meeting the requirements of its stakeholders. It is essential in this area, to identify the stakeholders and to find out how to measure their interests during execution of a complex project, such as space projects, (Loureiro, 1999).

Space systems projects consists in quite specific enterprises due to complexity, high costs involved, use of brand new technologies in order to develop equipment for operation in adverse environments, as well as lack of possibility for repair the equipments, after its orbit operation started, (Loureiro, 1999).

For this type of project, is considered utmost importance to have an AIT organization with mature and welldefined processes wherefore meeting stakeholder requirements. To meet these requirements it is imperative identify stakeholders concerns, wishes, desires and goals, and also characterize and manage the stakeholders that affect or are affected by the product development.

The development of a method to evaluate the readiness of the AIT organization with a focus on the stakeholders requirements can be provided as a tool for quality assurance of the provided services. Evaluation of the readiness of the AIT organization to meet the requirements of its stakeholders.

First author: isomar.slima@gmail.com 


\section{BIBLIOGRAPHIC REFERENCE}

\subsection{Stakeholder analysis and management}

For Clarkson (1995), Donaldson and Preston (1995), Rowley (1997), Scott and Lane (2000) and Baldwin (2002) Mainardes et al. (2010), the concept of stakeholder management was developed to aim organizations to recognize, analyze and examine the characteristics of individuals or groups that has potential to influence or are influenced by an organization, such as its organizational behavior. For the authors listed above, the organizational management is done into three levels: stakeholders' identification; the development of processes that help to raise the stakeholders' needs and interests, and the construction of relationships between all stakeholders.

Stakeholder analysis can be considered as a continuous process of data collection and analysis from interested parts, their tendencies and preferences, (Mitchell et al., 1997; Wood, 1990). For (Freeman, 2010), stakeholder analysis is a set of activities that should take into account prompt questions such as: who are the stakeholders? What they want? How will they try to achieve what they want? The cited questions are related to the attributes, purposes and methods used by stakeholders. This analysis is important to purchase the stakeholders knowledge influence in the project feasibility to determine the conflicts of interests between stakeholders involved.

\subsection{Assembly, Integration and Testing}

AIT (Assembly, Integration and Testing) ensures that all design parameters and specified performance will be achieved. To reach this, all the environmental conditions which the satellite will be submitted to are simulated, from launch to orbit operation, (LIT-INPE, 2015).

According to the life cycle of NASA projects, AIT activities are included into the phase D of a space project. The life cycle comprises the following phases:

- Pre-Phase A: Design Studies - Conceptual studies and identification of viable alternatives in the form of simulations, analyzes, study reports, models for the project;

- Phase A: Development of concept and technology -At this stage the definition of system concept and technology are presented in the manner of simulations, analysis, engineering models and mockups and trade study definition;

- Phase B: Preliminary Project - Establishment of a preliminary project or initial baseline, capable of mission needs. It establishes the development of necessary technology, the system requirements and design requirements in addition to managing a preliminary design for each final structure project of the system;

- Phase C: Final design and manufacturing - Completion of the design and construction of its associated subsystems, including their operating systems. Manufacture of hardware and software coding and components of the system;

- Phase D: AIT and release - Performs the implementation of Assembly, Integration and Product Testing of the final product or system. Initiate and prepare for launch and for product operation;

- Phase E: Operations and maintenance - This phase is implemented in the mission operation plan and mission is conducted, while proper maintenance of the system is carried out;

- Phase F: Discard or Decommissioning- On this stage the systems decommissioning and disposal scheme, developed in Phase E, are implemented. The data collected from the system is analyzed.

According to (NASA, 2007), each phase has its respective revisions, being the revisions of phase D as follows:

- FRR - Flight Readiness Review: Provides tests analysis, demonstrations and audits to determine the system's readiness for a safe and successful flight or launch and for subsequent flight operations; 
- ORR - Operational Readiness Review: This review checks the current system characteristics and procedures used in the system operation or in the final product. It ensures that all hardware, software, personnel, procedures, system documentation and support documents reflect accurately the implanted state of the system;

- SAR - System Acceptance Review: Verifies completeness of specific end products in correlation with expected maturity level and assure stakeholder expectations scope;

- TRR - Test Readiness Review: Ensures that test item (hardware / software), test installation, and testing procedures are ready to Test and Acquisition, Reduction and Control of data.

The AIT activities and reviews, requires specialized technical expertise with the goal to achieve a high degree of confidence in order to assure the product accordance with specified parameters, it is required professionals from different areas and several stakeholders. These professionals/stakeholders have distinct interests however it converges to the same purpose, to ensure high reliability level and accurate satellite operation. Some of the main stakeholders are shown in figure 1.

Figure 1. Stakeholders in AIT.

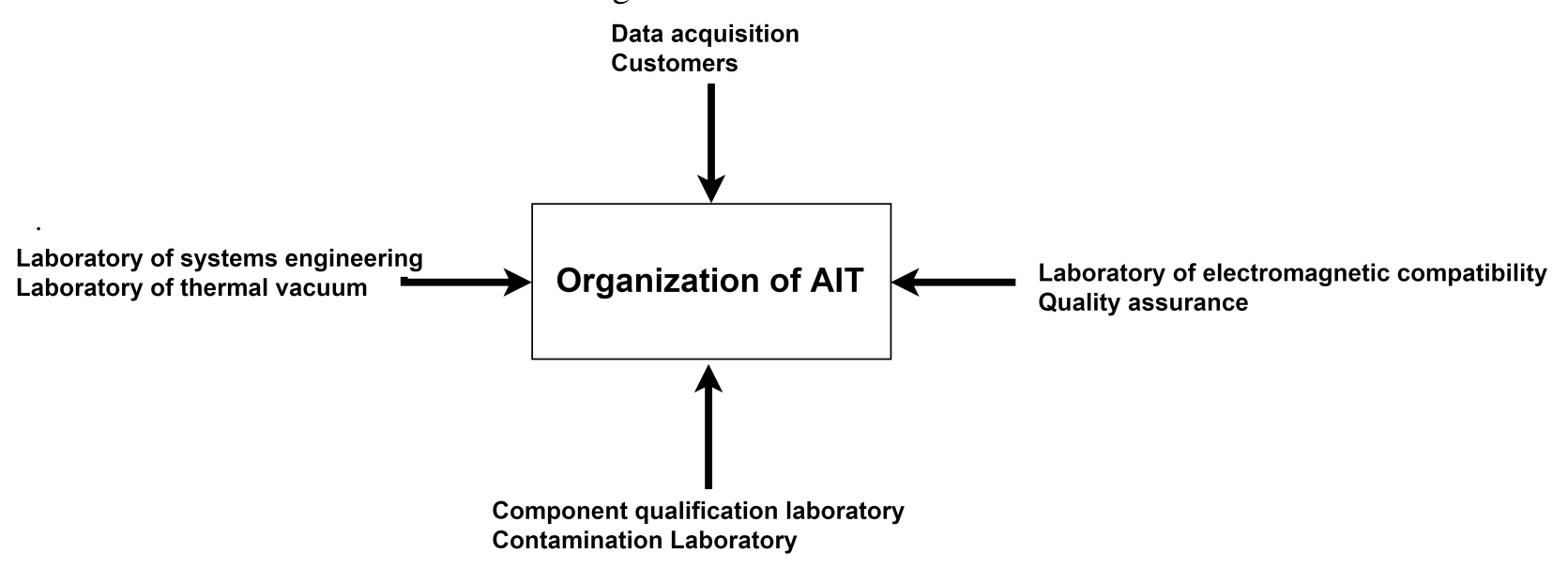

Source: Author (2019).

When known who the stakeholders of each AIT project are, allows to differentiate your interests, allows leveling the expectations besides enable comprehension of best way to deal with. Silva Jr (2011) describes the AIT activities:

- Assembly: Includes the mechanical operations performed to position, fix and interconnect physically each one of the units that belongs the satellite system.

- Integration: Activities of interconnection and functional verification between the units which constitute a subsystem, and between the subsystems which compound the system.

- Test: This is a sequence of experiments with the aim to verify the design requirements are satisfied and whether the satellite will endure both launching and orbiting hard operations during the estimated time for its activities.

\subsection{Readiness}

The concept of readiness resembles the definition of capacity and maturity being the competence to efficiently repeat a list of results in a predictable manner through mature and consolidated processes (CMMI, 
2018). On the other hand, the concept of readiness can be applied focused on the technological issue, for example TRL's technology readiness levels, which consist of a method that allows the certain technologies maturity estimation, (ESA, 2008).

In the same line of reasoning, it is possible to affirm that Readiness can be used to measure the level of maturity or evaluate something development such as: works, systems, processes, and technologies. Therefore, when level of readiness is determined it helps management and stakeholders in decision making regarding progress, capacity and technology development inside of an organization and thereby avoid problems related to implementation and budget commitment.

\subsection{Maturity and capacity definition}

Maturity and capacity is the competence to prevent the repetition of results list through mature and consolidated processes and also the competence to manage the development, acquisition and maintenance of products and services effectively (CMMI, 2018).

The maturity level of the company reveals its competitive and innovation capacity to obtain advantages in the development of differentiated products and services. The CMMI (Capability Maturity Model Integration) establishes five levels of maturity and capacity of a company. Each level is a predefined set of process areas, which indicates the organization's processes degree of maturity at a specific time (CMMI, 2018). See Figure 2.

Figure 2. CMMI Levels.

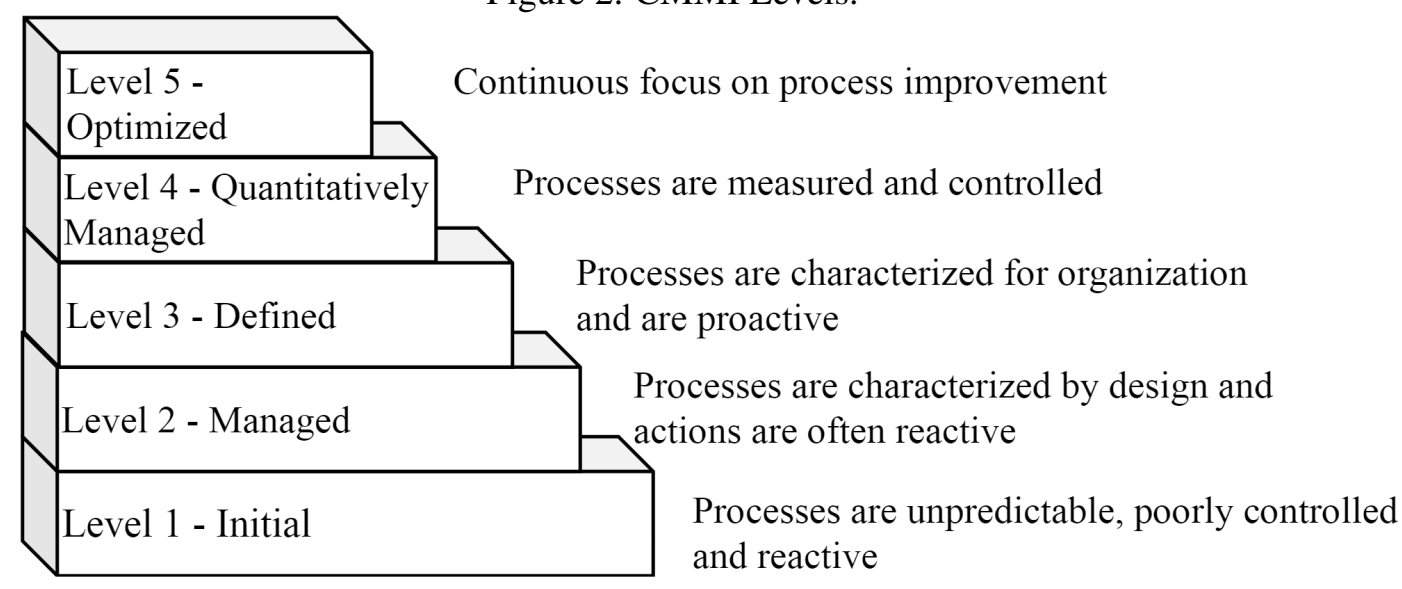

Source: Adapted from CMMI (2018).

The maturity of an organization is closely linked to the capacity of its processes. When level of maturity and capacity is needed, a methodology is required to evaluate processes capacity and at the same time provide a link to the organization's strategic objectives, by identifying priorities (CMMI, 2018). To obtain success, it is necessary to know the current maturity stage of the organization as well as its ability to deal with new management techniques.

\subsection{Measurement readiness metrics}

Readiness Levels (RL) consist of a set of metrics that allow the evaluation of certain aspects in the organization, project or system as follows: system readiness, technology readiness, integration readiness, manufacturing readiness, and programmatic readiness.

For the assessment of technological readiness, the commonly used metric is the TRL (Technology Readiness Level). This is a set of management metrics that allows the maturity evaluation of certain technology, and a consistent comparison of maturity between different types of technology, in the scope of a specific system, application and operating environment (ESA, 2008).

The technological readiness levels were stipulated to provide a common metric. Through the knowledge of maturity of new technologies is possible to communicate program executives, system developers and technol- 
ogy researchers among individuals from different organizations (ESA, 2008).

Regarding the readiness levels, each technology project is evaluated in relation with the parameters for each technology level, and receives a TRL classification based on the project progress. As well as ESA, NASA also uses a TRL scale composed by 9 readiness levels, where TRL 1 presents the scientific research at the beginning with its results being translated into research and future development. TRL 2 have been studied the basic principles and the practical applications can be implemented to the initial discoveries. TRL 3 performs analytical and laboratorial studies to confirm if a technology is feasible and / or is ready to proceed through the development process, this is the level where a proof-of-concept model is usually built. TRL 4, tests several components to demonstrate interoperability between each other. The TRL 5 is a continuation of the TRL4, however, a technology identified in 5 as a breadboard technology must perform more rigorous tests. In TRL 6 a fully functional prototype or representational model of the technology is developed, going to TRL 7 the technology cited will require a working model or prototype being demonstrated in a spatial environment. TRL 8 presents the technology tested and "qualified for flight" being ready to be implemented. Finally if the technology is proven in-flight during a successful mission is called TRL 9. Besides TRL, there are other tools that was developed with the purpose of establishing readiness metric such as:

- System Readiness Levels (SLR) quantifier to assess the system readiness with regards to the complexity or compatibility of component integration (Sauser et al., 2010).

- Integration Readiness Levels (IRL) assesses the readiness of integration between the technological elements of a system through integration maturity level on a scale similar to TRL in order to be used in conjunction with Technology Readiness Assessments (TRA) to provide an assessment of the system readiness level (Gove, 2007; Sauser et al., 2010).

- Manufacturing Readiness Levels (MRLs) evaluates the maturity of manufacturing readiness (products and manufacturing processes) or the capabilities from potential suppliers. The quantitative measure of MRLs are used to assess the maturity of a given technology, component or system by manufacturing perspective (Wheeler e Ulsh, 2010).

- Programmatic Readiness Levels (PRL) assesses readiness or concerns from program management, such as programmatic milestones documentation considered vital to successful development of technology products (Altunok e Cakmak, 2010).

\section{RESEARCH METHODOLOGY}

The bibliographical research presents qualitative and quantitative aspects, with experimental disposition applied in a case study for the application of the proposed method. For this, methodological objectives follow steps already taken and others that will complement the research development, such as:

- Bibliographic review with the application of a literature systematic review with string research performed in the main databases;

- Study of norms and academic works of the space product warranty area (dependability, safety assurance, software assurance, product engineering) regarding readiness during phases of assembly, integration, and testing of spatial products;

- Identification of the needs of the AIT organization;

- Identification of stakeholder requirements for AIT organization;

- Structuring and developing of proposed evaluation method;

- Application of the method of readiness evaluation in the LIT (Laboratory of Integration and Testing) located at INPE (National Institute for Space Research). 


\subsection{Proposed method}

The framework will consist of a methodology for assessing the readiness of an AIT organization in a system level, to meet the requirements of its stakeholders, ensuring that their needs are clear and comprehended before starting AIT activities. Correlating requirements stemming from Assembly, Integration and Testing of satellites, with stakeholders' requirements in relation to their activities, infrastructure and process of AIT organization applied to its product (satellite). Thus elaborate an AIT Readiness index.

This method, presented by a framework, can be used as a reference model and support all stages of AIT activities of a space product (engineering models, qualification, flight model, protoflight), from the perspective of stakeholder requirements from Assembly, Integration and Testing organizations that perform assembly and testing of subsystems and space systems. Figure 3 shows an generic model of the proposed method.

Figure 3. Generic model of the proposed method.

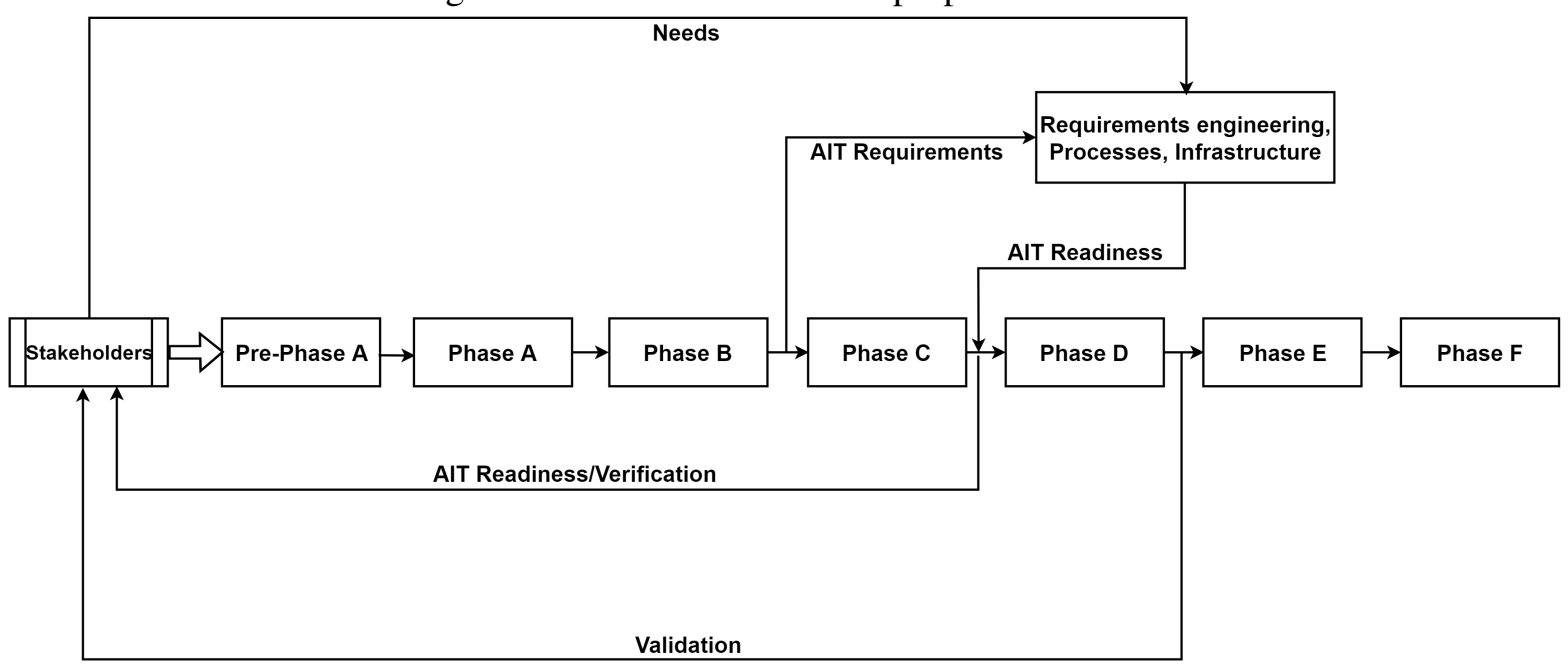

Source: Author (2019).

The proposed method will provide the possibility to measure the level of readiness of an AIT organization, identifying its evolution direction by applying the criteria of excellence to be defined (similar case: the Malcolm Baldrige Prize). Rotating around, are the vital aspects for any type of organization, for example: leadership, strategy, customers, knowledgement, people, processes and results. The detailed application, of the cited excellence criteria's in pursuit of readiness, is complex but effective.

The organization of AIT will be evaluated considering the parameters established for each level of readiness, and then a RL (Readiness Level) rating will be given based on the developed projects progress.

This classification shall indicate the system-level competencies that an AIT organization needs to have or to develop to perform satellite Mount, Integrate and Test.

The readiness levels will be established following the CMMI examples that establish five levels of maturity. This analysis will prove the capacity that a company can meet, referenced in Figure 2. Each level is a predefined set of process areas, which indicates the degree of maturity of the processes at a specific phase.

For a company to succeed in the global market during phase of products and services development, it is essential to had reached a high level of maturity by proving its competitive and innovative capacity.

Tables 1 and 2 present a possible adaptation of the CMMI process areas to meet the requirements of the here cited proposed method.

Table 1 shows that the process areas "Process management", "Project management" and "Engineering" can be adapted to "Process readiness", "Management of readiness" and "AIT readiness", this approach will be adopted for the other CMMI characteristics until the proposed method be achieved. Table 2 presents the possible processes to be created with their respective categories and also the readiness levels. 
Table 1. Example of process area categories correlated between CMMI-DEV and PRONT-AIT.

\begin{tabular}{|l|l|}
\hline CMMI-DEV & PRONT-AIT process areas \\
\hline \hline Support & Support \\
\hline Process management & Process readiness \\
\hline Project management & Management of readiness \\
\hline Engineering & AIT readiness \\
\hline
\end{tabular}

Source: Author (2019).

Table 2. Example of Process Areas, Categories and Maturity Levels of PRONT-AIT.

\begin{tabular}{|l|l|l|l|}
\hline ID & Process Area & Category & Readiness Level \\
\hline \hline AP01 & $\begin{array}{l}\text { Configuration Manage- } \\
\text { ment }- \text { CM }\end{array}$ & Support & 2 \\
\hline AP02 & $\begin{array}{l}\text { Organizational Process } \\
\text { Definition-OPD }\end{array}$ & Process readiness & 3 \\
\hline AP03 & $\begin{array}{l}\text { Quantitative Readiness } \\
\text { Management }- \text { QRM }\end{array}$ & $\begin{array}{l}\text { Management of readi- } \\
\text { ness }\end{array}$ & 4 \\
\hline AP04 & $\begin{array}{l}\text { Development of AIT Re- } \\
\text { quirements }\end{array}$ & AIT readiness & 3 \\
\hline
\end{tabular}

Source: Author (2019).

\section{RESULTS}

The work is currently in its initial phase of study, when the first systematic review data are being extracted. This review is carried out focusing on studies that deal with model theories such as engineering, qualification, flight and protoflight, academic standards and studies in the area of space product assurance (dependability, safety assurance, software assurance, product engineering) as well as topics addressing readiness, during the Assembly, Integration and Testing phases of spatial products.

\section{FINAL CONSIDERATIONS}

The readiness of an AIT organization to attend its stakeholders' requirements considering projects, such as space projects is a challenge. This is type of organization requires excellence performance, different technologies connections in various subsystems sizes, high-quality material and manufacturing inputs, testing, integration, and high level of specialized workmanship, going through long cycles of design and development. In case failure occurs, implications will be hard to deal with. All the diverse aspects involved in this area and the factors above-mentioned make the challenges of this work complex.

\section{REFERENCES}

Altunok, T. e Cakmak, T., 2010. "A technology readiness levels (trls) calculator software for systems engineering and technology management tool". Advances in Engineering Software, Vol. 41, pp. 769-778. doi:10.1016/j.advengsoft.2009.12.018.

CMMI, T.P., 2018. "CMMI $\AA$ for Development, Version 2.0: Driving performance through capability. CMMIDEV, V2.0." Relatório técnico, Carnegie Mellon University. URL http://www.sei.cmu.edu/ library/abstracts/reports/10tr033.cfm.

ESA, 2008. “TECHNOLOGY READINESS LEVELS HANDBOOK FOR SPACE APPLICATIONS”. , No. September. 
Freeman, R.E., 2010. Strategic management: a stakeholder approach. Cambridge University Press, Cambridge. ISBN 978-0521151740.

Gove, R., 2007. Development of an Integration Ontology for Systems Operational Effectiveness. Tese de Pós-Doutorado, Stevens Institute of Technolog.

LIT-INPE, 2015. "Montagem, Integração e Testes de Satélites". URL http://www.lit.inpe.br/ pt-br/montagem \{_\}integracao \{_\}e\{_\}testes \{_\}de \{_\}satelites.

Loureiro, G., 1999. A systems and concurrent engineering framework for the integrated development of space products. Tese de Pós-Doutorado. doi:10.1016/S0094-5765(02)00272-2.

Mainardes, E.W., Alves, H., Raposo, M. e Domingues, M.J., 2010. "Categorização por importância dos stakeholders das universidades". Revista Ibero-Americana de Estratégia - RIAE, pp. 4-43. doi:http: //dx.doi.org/10.5585/riae.v9i3.1681.

Mitchell, R.K., Wood, D.J. e Agle, B., 1997. "Toward a theory of stakeholders identification and salience: defining the principle of who and what really counts". Academy of Management Review, Vol. 22, No. 4, pp. 853-886. ISSN 03637425. doi:10.5465/AMR.1997.9711022105.

NASA, 2007. NASA Systems Engineering Handbook. Washington, D.C., rev1 edição.

Sauser, B.J., Gove, R., Forbes, E. e Ramirez-marquez, J.E., 2010. "Integration maturity metrics : Development of an integration readiness level". Information Knowledge Systems Management, Vol. 9, No. 1, pp. 17-46. ISSN 1389-1995. doi:10.3233/IKS-2010-0133.

Silva Jr, A.C., 2011. "Amazonia 1 assembly, integration and test plan”. doi:A827000-002-001.

Wheeler, D. e Ulsh, M., 2010. "Manufacturing Readiness Assessment for Fuel Cell Stacks and Systems for the Back-up Power and Material Handling Equipment Emerging Markets". , No. February, pp. NREL Technical Report TP-560-45406.

Wood, D.J., 1990. Business and Society. Longman Higher Education-Average Customer Review, Pittsburgh. ISBN 0673384357. 